\title{
AS TENSÕES CONTEMPORÂNEAS DA AMÉRICA LATINA EM PERSPECTIVA HISTÓRICA
}

Andrés Donoso Romo

Resumo: O artigo delineia o marco histórico dos principais problemas contemporâneos da América Latina, observando as tensões que afetaram a cultura, a economia e a política. Privilegia-se a abordagem dos problemas que se impuseram à população devido ao aprofundamento da industrialização e da urbanização, ao desenraizamento identitário, às agudas iniquidades na distribuição da riqueza e à proliferação da violência política exercida sob a forma de ditaduras e guerrilhas.

Palavras-chave: América Latina, História Contemporânea, Tensões Culturais, Econômicas e Políticas.

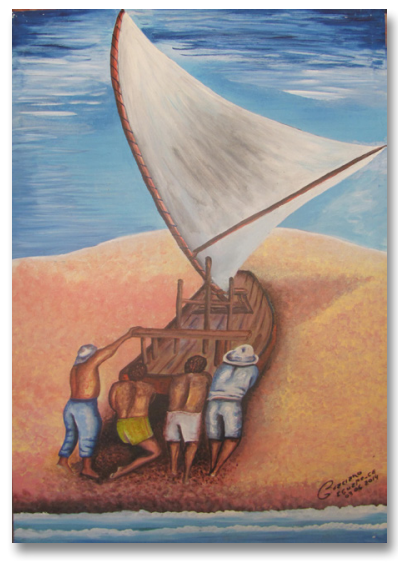

\section{LATIN AMERICA CONTEMPORARY TENSIONS IN HISTORICAL PERSPECTIVE}

\footnotetext{
Andrés Donoso Romo

Doutor em Integração da América Latina pela Universidade de São Paulo. Pesquisador do Centro de Estudos Avançados da Universidade de Playa Ancha, Valparaíso, Chile.
}

\begin{abstract}
The article outlines the historical landmark of the major contemporary problems of Latin America, noting the tensions affecting the culture, the economy, and politics. It focuses on addressing the problems imposed on the population due to the expansion of industrialization and urbanization, the uprooting of identity, the acute iniquities in the distribution of wealth, and the proliferation of political violence exerted in the form of dictatorships and guerrilla warfare.

Keywords: Latin $\begin{aligned} & \text { America, } \\ & \text { Contemporary }\end{aligned}$ History, Cultural,
Economic and Political Tensions.
\end{abstract}




\section{TENSÕES CULTURAIS NOS INÍCIOS DE NOSSA CONTEMPORANEIDADE}

Nos finais do século XIX e princípios do XX, as profundas mudanças ocorridas nas formas de trabalho e no modo de vida da população, provocadas pelo início da industrialização e da urbanização, são tidas como alguns dos principais indicadores de que, nesses anos, começa a época contemporânea da América Latina. Entende-se, por sua vez, que a intensificação destas transformações no tempo, tanto quanto as problemáticas surgidas com elas, foram responsáveis para que muitas das dimensões da realidade enfrentassem sucessivas crises que, ao se somarem, foram dando forma a um cenário onde a violência, em todas as suas manifestações, foi tornando-se cada vez mais protagonista. ${ }^{1}$

Com o objetivo de facilitar a exposição destas interpretações sobre a história recente da América Latina, se diferenciarão três dimensões, a saber: a cultural, a econômica e a política. E em cada uma delas se descreverá, sobretudo, a mecânica que fazia com que os conflitos se tencionassem até desembocar em situações limite e/ou momentos críticos. Questão que permitirá, ao final do artigo, formarmos uma ideia dos principais problemas que afetavam a região ou, a partir de outro ponto de vista, obter uma noção das preocupações que estavam movimentando as melhores energias de grande parte dos atores sociais, inclusive os intelectuais.

Com o propósito de atingir um nível adequado de profundidade histórica, a análise de cada uma destas dimensões privilegiará um marco temporal diferente. A dimensão cultural será abordada tendo em vista os acontecimentos que se sucederam desde o final do século XIX até a década de 1910; a dimensão econômica será examinada tendo como referência os anos transcorridos entre as duas guerras mundiais (1914-1945); e o âmbito político

1 O entendimento de que a história contemporânea da América Latina começa no final do século XIX é compartilhada, entre outros autores, por Pablo González Casanova (1985, p. 11) e Roberto Fernández Retamar (2006, p. 39). A noção de que seriam as transformações na forma de trabalhar e de viver da população algumas das chaves para compreender esta mudança de época tem sido trabalhada, com mais profundidade, em duas obras anteriores de minha autoria, ver Donoso Romo (2012). 
será estudado sobre o pano de fundo dos eventos ocorridos desde meados do século XX até a década de 1980. Tal recorte condiz, ademais, com os momentos em que cada uma das dimensões apresentou maior notoriedade.

Tanto a identidade das pessoas quanto a cultura das coletividades começam a mudar, com diferentes intensidades, conforme começam também a se transformar os modos de produção e de assentamento. Desde meados do século XIX, quando se introduziram as primeiras ferrovias na região, até a inauguração do canal do Panamá em 1914, a industrialização irrompe vigorosamente em diversos países latino-americanos. Ela foi responsável pelo aumento constante na produção de matérias-primas que serviram de base para a produção em maior escala dos trens e barcos a vapor.

Por que a industrialização apareceu com tanta força? Os inícios da modernização e da mecanização dos processos produtivos, tanto agrários como mineiros, foram motivados, fundamentalmente, pela alta demanda de matérias-primas e produtos agrícolas por parte dos países onde se verificou a primeira industrialização. Logo após este impulso inicial, estes processos continuaram se aprofundando para satisfizer as demandas daqueles que se beneficiavam com o comércio internacional e também dos que ingressavam nos domínios da economia monetária, ou seja, os cada vez mais numerosos habitantes dos centros povoados, que já não produziam diretamente seu sustento, pois trabalhavam em troca de salário. Isso fez com que, aos poucos, aparecessem empresas dedicadas a consertar as novas máquinas a vapor, o que acarretou, paulatinamente, na substituição das oficinas por pequenas fábricas que proviam artigos de consumo frequente, como roupa ou comida. Ao aprofundarem-se estas dinâmicas, no decorrer do século XX, fizeram-se necessárias também as indústrias de peças e motores, pois essas mesmas máquinas necessitavam ser produzidas ou reparadas.

Todas essas transformações foram responsáveis pela superação dos períodos em que a vida das pessoas esteve associada predominantemente ao trabalho agrícola. A partir do final do século XIX, verificou-se um aumento significativo e gradual da 
atividade industrial, seguido de um incremento ainda mais substancial no setor de serviços e um decréscimo acentuado na agricultura. Ainda que diminuísse proporcionalmente o número de pessoas vinculadas ao trabalho agrícola, sua produtividade cresceria de maneira constante devido à introdução de novas tecnologias no campo. Se nos finais do século XIX a força de trabalho se vinculava majoritariamente ao setor agrícola, na década de 1980 essa situação se manteria inalterada apenas na Guatemala, em Honduras e no Haiti.

De todas as consequências que trouxe o início da industrialização, se entende que a mais relevante, em termos sociais e culturais, foi a apropriação sistemática das terras dos indígenas e camponeses, levada a cabo pelos setores dirigentes, quase sempre por meio de métodos indevidos, com o fito de introduzi-las nos circuitos do capitalismo mundial, tal qual ocorreu no extremo sul do Chile e da Argentina, na área litorânea Caribe da América Central e, a partir de então, também na grande floresta amazônica.

Os habitantes originários que conseguiam sobreviver aos despejos tenderam a sofrer dois destinos: uma parte encontrou seu futuro dentro dos esquemas produtivos impostos pelos vencedores, inserindo-se como escravos ou como semiassalariados. Outra parte, a grande maioria, viu-se obrigada a migrar às cidades que foram aparecendo em volta das estações e dos portos, inaugurando assim as migrações campo-cidade.

Independentemente dos motivos particulares que levavam as pessoas a migrar, as razões de ordem econômica sempre tiveram um peso decisivo. Queria-se tanto deixar para trás a violência rural quanto desfrutar das oportunidades que se dizia haver nas cidades, mas se desejava, sobretudo, fugir da miséria. As melhorias nos transportes estiveram intimamente relacionadas a essas migrações, uma vez que os mesmos meios de transporte que carregavam todo tipo de mercadorias levavam os desalojados que nunca mais voltavam, movimentos que se verificavam em escala local, nacional e inter-regional, nessa última porque em muitos dos principais portos e cidades da região vieram morar desalojados rurais oriundos do sul da Europa. 
Ao chegar às cidades, esses imigrantes se amontoavam nas antigas casas centrais e, quando essas não eram suficientes, começavam a construir moradias precárias em áreas marginais. Concomitantemente, as elites iniciaram um afastamento paulatino dos centros urbanos para instalar-se em conjuntos residenciais particulares, enquanto os novos setores médios se instalavam em áreas situadas ao redor dos principais entroncamentos urbanos, como praças, mercados ou quarteis.

Graças aos novos habitantes, bem como às sucessivas melhoras nas condições sanitárias, os portos e as cidades cresceram assombrosamente. Melhoras que foram tão importantes que a expectativa de vida passou de 29 anos, no início do século XX, para 47, em meados do mesmo, e para 67, na década de 1980. Esse aumento da população urbana foi inversamente proporcional à diminuição da população rural, pois, se na alvorada do século $\mathrm{XX}$, menos de um quinto da população residia em cidades, ao final deste período a situação era inversa.

Como se observará a seguir, a sucessão de mudanças no plano econômico e social precedeu as transformações culturais. ${ }^{2}$ Fatores como a violência rural, a migração forçosa, o desemprego e a exploração, faziam com que as pessoas se voltassem para as fontes tradicionais de conhecimento (as autoridades políticas ou religiosas) em busca de respostas ou de alívio. Como tais fontes frustravam as expectativas dos indivíduos, pois também enfrentavam situações desconhecidas, tornaram-se alvo de críticas. Como a resignação não melhorava em nada as coisas, aos poucos se começava a assumir que as penúrias não eram naturais e a compreendê-las como assuntos que precisavam ser enfrentados. A secularização começava assim a se fortalecer em um movimento

$2 \quad$ Algumas das principais manifestações dos problemas rurais e urbanos desse período podem ser encontradas em Donoso Romo (2012, p. 23-28). No entanto, algumas pistas para avaliar as dificuldades que enfrentou a população rural e as respostas que tiveram frente a suas demandas a partir da década de 1930 podem ser consultadas, especialmente, em De la Peña (1997, p. 197, 224 e 225) e Palacios (2008, p. 64 e 65). Sobre as estreitas perspectivas dos setores populares na cidade depois da década de 1930 e algumas das manifestações dos descontentes e seus resultados, veja-se especialmente Roxborough (1997, p. 141 e seguintes). 
paralelo ao que fazia crescer a influência do Estado em detrimento do poder da Igreja. ${ }^{3}$

Nessa espécie de "vácuo cultural" ressurgiu, quase cem anos depois de terem começado os processos de independência na América Latina, o culto à ideia de nação. Os meios de comunicação, como os jornais e os periódicos, assim como a crescente educação pública, foram os principais responsáveis pela difusão eficaz dos enunciados nacionalistas das elites, tarefa que realizaram com sucesso, a ponto de tornar a nação um motivo mais que suficiente para matar ou morrer com honra, tal como o provam as guerras do final do século XIX em que tomaram parte chilenos, peruanos, bolivianos, paraguaios, brasileiros, argentinos e uruguaios.

Entretanto, os discursos nacionalistas difundiram-se não apenas porque os marcos interpretativos tradicionais foram ineficazes em sua missão de fornecer explicações adequadas para entender os novos processos vividos, mas também porque possuíam, como ainda hoje o possuem, quatro características que os tornavam irresistivelmente sedutores. Eram amplos e ambíguos, o que fazia que pudessem se ajustar aos diagnósticos de um grande espectro dos receptores. Tendiam a apelar para as emoções e sentimentos, o que gerava grande repercussão em seus destinatários. Falavam em nome de toda a população à qual diziam representar, o que tornava fácil o sentimento de inclusão na coletividade. E, finalmente, identificavam empreitadas de bem comum que outorgavam um sentido ulterior, tanto às ações empreendidas quanto às dificuldades enfrentadas.

Dentro dos discursos de feição nacionalista houve alguns que se destacaram, como o do latino-americanismo. As intervenções dos Estados Unidos na América Central e no Caribe, mais especificamente seu papel na emancipação de Cuba no ocaso do século

3 Autores da estatura de Germán Rama (1987a, p. 32; 1987b, p. 194) e Eric Hobsbawm (2003, p. 317, 334 e 335) são tomados como base para identificar este "desajuste" entre tradição e realidade que afetou às populações rurais nestes tempos de mudanças produtivas e sociais. A ideia de que frente a esta adversidade nasceu a necessidade de sobrepor-se à resignação para enfrentarlhe, o desenvolvemos em outro trabalho, ver Donoso Romo (2012, p. 37-39). 
XIX e sua atuação na separação da Colômbia e do Panamá no despontar do século XX, foram duramente condenadas neste lado do continente, sobretudo pela intelectualidade. Enquanto os estadunidenses justificavam suas ações com uma retórica nacionalista, que as entendia como necessárias para salvaguardar seus interesses, aqui elas eram consideradas tentativas ameaçadoras de re-colonização que não se deteriam até abranger todo o continente, tachando-as de nacionalismo patológico ou imperialismo. ${ }^{4}$

Assim como as intromissões dos Estados Unidos não cessaram, pois foram frequentes as incursões militares na zona meridional do continente, a condenação dessas atuações tampouco cessou. O cubano José Martí e o uruguaio José Enrique Rodó são lembrados pela historiografia como os principais precursores do latino-americanismo contemporâneo, o qual irá expandir-se até nossos dias graças, entre outras vias, às viagens, revistas e encontros intelectuais. ${ }^{5}$

Portanto, na medida em que foram se consolidando as transformações econômicas e sociais que afetaram a região, e ainda mais com as dificuldades que elas acarretaram, a dimensão cultural ganhou paulatinamente relevância. Enquanto as fontes tradicionais de conhecimentos se revelavam ineficazes, o ideário da nação foi ingressando nos corações e mentes da população regional e, junto com ele, um vocábulo novo começou a popularizar-se

4 As agressões perpetradas nesses anos na América Central e no Caribe são bem estudadas em Bosch (2009, p. 735), no entanto um olhar integrador que inclui um marco temporal e geográfico mais abrangente pode ser encontrado em Sader (2000, p. 34-39). Enquanto a interpretação a respeito de que as ações estadunidenses se justificariam com uma retórica nacionalista, ela se constrói principalmente graças ao trabalho de Edward Said (1999, p. 19 e 25). A compreensão de que neste lado do continente ela seria concebida como nacionalismo patológico se deduz de uma frase do argentino Ricardo Rojas em Funes (2006, p. 95). Interpretações esboçadas, também, em Donoso Romo (2012, p. 62 e 63).

5 Onde mais claramente são expostas as concepções antiimperialistas destes autores é no livro Ariel, publicado originalmente em 1900, veja-se Rodó (1976), e na obra Nuestra América, de 1891, veja-se Martí (1973). A interpretação de que o pensamento latino-americano teria crescido ao longo do século graças às viagens, revistas e encontros intelectuais se constrói principalmente com base no trabalho de Devés (2000, p. 107, 168 e 178) e tem sido exposta com profundidade em Donoso Romo (2012, p. 53-59). 
durante todo o século XX: América Latina. Nossas sociedades tinham deixado de ser o que eram e, nesse movimento, que continua a ocorrer, a busca de sentido, a pergunta pela identidade, tornaram-se assuntos que até hoje nos convocam.

\section{TENSÕES ECONÔMICAS NOS ANOS DAS GRANDES GUERRAS MUNDIAIS}

Ainda que os discursos nacionalistas conseguissem se instalar, efetivamente, como marcos para compreender as dificuldades sofridas com as mudanças econômicas e sociais sucedidas desde as últimas décadas do século XIX, com o passar dos anos as problemáticas que afetavam aos latino-americanos não deixaram de crescer. Dentre os fatores que mais contribuíram a este agravamento se destaca o instável cenário comercial internacional, o qual estava profundamente afetado pelos conflitos inter-imperialistas que ocorriam no hemisfério norte e no qual as duas guerras mundiais e a crise econômica que explodiu em 1929, foram as que tiveram consequências mais visíveis.

O modo como este panorama instável afetou as economias latino-americanas pode ser compreendido por meio da seguinte consideração: nesses anos caíram abruptamente as vendas de uma parte substancial dos bens primários que nossos países comercializavam, devido a mudanças nas prioridades comerciais dos principais mercados compradores, também ao fato de que não pudemos superar as barreiras protecionistas que esses levantaram e ainda por conta da forte diminuição do comércio transatlântico produzido pelo temor das ações bélicas das armadas beligerantes. Isto se traduz em uma baixa na quantidade de divisas que ingressavam na região e, mais importante ainda, em uma diminuição significativa dos erários públicos, pois estes se constituíam em grande parte dos impostos sobre as exportações.

Conforme podemos imaginar, os efeitos destas turbulências comerciais não somente se manifestaram no plano econômico. Ao lado do desemprego surgiu a instabilidade política e, ao lado dessa, a violência. Dentre as consequências mais dramáticas da crise de 1929, por exemplo, está a insurreição popular ocorrida em 
El Salvador, em 1932, em que a queda do preço do café, seu principal produto de exportação, provocou uma paralisação de atividades que alcançou $40 \%$ da população trabalhadora em algumas zonas do país. Nestas condições, a fome não tardou a aparecer e sua persistência manifestou-se em uma revolta que só foi aplacada depois de soldados tirarem a vida de dezenas de milhares de indígenas e camponeses.

Como resposta às turbulências da economia internacional, os estados latino-americanos começaram a assumir um papel cada vez mais relevante. Atentos à experiência bem sucedida da União das Repúblicas Socialistas Soviéticas, a qual pôde sair imune da crise de 1929 graças a sua economia centralizada, os responsáveis políticos e econômicos de nossos países começaram a pôr em prática uma ideia que será chave nas próximas décadas: a planificação. Amparados na convicção de que as consequências das crises econômicas podiam ser evitadas, as autoridades se propuseram reorientar as forças produtivas para aumentar tanto a quantidade de postos de trabalho quanto de mercadorias. Isso se conseguiria, pensaram, aprofundando a industrialização. Desde então, a atividade industrial passará a puxar os vagões das economias regionais, questão que era, certamente, diametralmente oposta ao que ocorrera nas décadas precedentes, em que ela só ecoava o dinamismo do setor primário exportador.

Para favorecer a industrialização, os estados se dispuseram a consolidar os recém criados bancos centrais e a erigir uma série de agências dedicadas ao fomento produtivo. Foi a partir destas instituições que começaram a emanar medidas pensadas para satisfizer estas finalidades, tais como a implantação de impostos diferenciados para as importações, a determinação de cotas de ingresso para certas mercadorias ou a venda de divisas a preços diversos segundo fossem os fins que se lhes daria.

À promoção da industrialização tornou necessário o aprofundamento dos processos de mecanização do campo, pois se considerava prioritário produzir mais alimentos para sustentar a crescente população urbana e, ademais, porque se afigurava improrrogável apaziguar os conflitos sociais derivados da grande quantidade de camponeses sem terra. Por isso, independentemente da 
orientação política dos governos, em todos os países latino-americanos discutiu-se a possibilidade de realizar uma reforma agrária, a mesma que (desde finais da década de 1930 e com maior intensidade nas de 1950 e 1960) foi levada a cabo em vários de nossos países. O pressuposto fundamental que esteve por trás deste tipo de reforma era o de que, quanto menor fosse a unidade agrícola, mais eficiente seria e mais postos de trabalhos geraria. Isso explica também que, não obstante existir uma grande heterogeneidade nas formas que esta reforma assumiu, todas propusessem pôr em uso as terras improdutivas mediante a expropriação de latifúndios e a mecanização dos processos produtivos por meio da introdução de novas tecnologias.

Ainda que não exista um julgamento unânime sobre as reformas agrárias, muitos analistas parecem concordar, por um lado, em que elas de fato conseguiram aliviar o descontento da população rural e, por outro lado, em que seus resultados produtivos não estiveram à altura do planejado. Dentre todas as dificuldades que enfrentaram, talvez a principal fosse a forte oposição por parte dos latifundiários. ${ }^{6}$

Durante aqueles anos os estados não só começaram a compreender-se como encarregados de regular, promover e fiscalizar os empreendimentos econômicos, como também passaram a considerar-se atores empresariais. Por isso é que, a partir da década de 1920, passam a dedicar-se à construção de grandes obras públicas, à provisão de serviços urbanos e à geração de energia. Função que respondia ao crescente interesse que manifestavam os estadistas em controlar tanto a produção quanto a distribuição de insumos avaliados como prioritários para a industrialização. O México tornou-se o país de referência nesses temas devido à nacionalização a que submeteu às petroleiras estrangeiras em

6 A efetividade política das reformas agrárias é um diagnóstico obtido em De la Peña (1997, p. 277) e Fals Borda (1979, p. 66, 83 e 84), no entanto, a ineficácia econômica se colige em De la Peña (1997, p. 241, 244 e 245) e Ffrench-Davis e outros (1997, p. 112). As dificuldades que enfrentaram estes processos, especialmente a resistência dos latifundiários, depreendem-se de BulmerThomas (1998, p. 371 e 372), Long e Roberts (1997, p. 310-320), Palacios (2008, p. 73) e Thorp (1998, p. 167 e 188). 
1938, apesar de já existirem experiências similares na Argentina dos anos vinte e de serem os cubanos, nos sessenta, os que efetivariam de maneira mais completa estes preceitos. $^{7}$

De onde vieram os recursos que tornaram possível todas estas medidas econômicas, o fortalecimento dos estados e a preeminência da industrialização? Na literatura especializada se identificam cinco estratégias diferentes para sustentá-las, cada uma das quais se agregava ou superpunha às anteriores, sem por isso anulá-las: usufruto dos capitais nacionais; fomento do investimento estrangeiro; acesso a empréstimos de fontes oficiais do exterior; promoção da integração regional e obtenção de empréstimos de bancos privados internacionais. A respeito dessas estratégias, é preciso fornecer alguns antecedentes.

Até meados do século XX, o fomento da industrialização se valeu principalmente de capitais nacionais, resultado das medidas que tendiam a favorecer as indústrias locais e das divisas obtidas pelas vendas daquelas matérias primas consideradas úteis pelas potências que participavam das guerras mundiais e que, precisamente pelos transtornos bélicos, não se utilizaram na compra de produtos manufaturados dos provedores tradicionais. ${ }^{8}$

Imediatamente depois de dirimido o conflito inter-imperial, normalizaram-se as relações comerciais norte-sul e se gerou uma confluência de interesses em torno da instalação de filiais de multinacionais na América Latina. Os especialistas regionais avaliavam-na favoravelmente, pois era necessário fabricar peças industriais, motores e maquinarias, quer dizer, aprofundar o processo de industrialização. De modo congruente, mas sob perspectiva diferente, os especialistas que provinham dos países que

7 A interpretação de que a atuação empresarial do Estado obedeceria a sua pretensão de favorecer a industrialização é obtida a partir de Thorp (1998, p. 153). Acerca dos empreendimentos empresariais ou fabris estatais podem-se obter antecedentes em Bulmer-Thomas (1997, p. 40; 1998, p. 270, 287, 492 e 493), Lewis (2008, p. 253 e 254) e Thorp (1998, p. 171). Sobre as nacionalizações apontadas tanto no México, na Argentina, em Cuba e o resto da América Latina, consulte-se Braun (2008, p. 371) e muito especialmente Bulmer-Thomas (1998, p. 305,400 e 411 ).

8 Sobre os recursos internos investidos na industrialização vejam-se, entre outras obras, Long e Roberts (1997, p. 287), Marichal (2008, p. 203 e 204) e Thorp (1997, p. 56). 
estavam saindo do conflito mundial, especialmente dos Estados Unidos, viam com bons olhos a possibilidade de ampliar o raio de ação de seus negócios exportando fábricas inteiras. Essas indústrias multinacionais, além de se depararem com mercados protegidos que lhes ofereciam mão de obra barata, viram reduzidos seus gastos oriundos da compra de insumos, pois muitos deles não tinham que ser transportados por grandes distâncias. Essas filiais obtiveram tantos benefícios que muitas indústrias locais terminaram sendo absorvidas por elas, como aconteceu com as automobilísticas, farmacêuticas e siderúrgicas no Brasil da segunda metade dos anos sessenta. Os benefícios foram tão significativos que, em alguns momentos, os capitais que exportaram, em forma de lucros, representavam valores cinco vezes maiores do que o montante de seus novos investimentos. ${ }^{9}$

Em parte pelo que já foi exposto, em parte porque o aprofundamento da estratégia econômica sempre exigiu novos recursos, e em parte também porque as problemáticas sociais que geravam a industrialização e a urbanização demandavam investimentos cada vez mais elevados, começou-se a julgar como necessária a ideia de que, em vez de alentar esses investimentos estrangeiros, deviam-se obter capitais do exterior que pudessem ser utilizados segundo critérios nacionais. Demanda que esteve presente em todos os fóruns regionais, desde o momento em que os Estados Unidos decidem efetivar uma medida de características similares para reconstruir Europa depois da segunda guerra mundial, mas que só foi colocada em prática depois do triunfo da ameaçadora revolução cubana no final dos anos cinquenta. Sob o nome de Aliança para o Progresso, os Estados Unidos comprometeram

9 Sobre o investimento estrangeiro direto nestes anos podem ser consultadas, entre outras, as obras de Ffrench-Davis e outros (1997, p. 140), Puyana (2008, p. 84) e Puyana e outros (2008, p. 171 e 172). A predominância econômica que adquiriram os Estados Unidos nestes anos, no nível regional, é bem descrita em Thorp (1997, p. 57; 1998, p. 106 e 137). As razões com que os diferentes envolvidos avaliavam o investimento estrangeiro direto podem ser sondadas em Galeano (1983, p. 229 e 270), Hobsbawm (2003, p. 265) e Thorp (1997, p. 81 e 82). No entanto, os olhares críticos sobre estes processos, que assinalam que eles acabaram com indústrias locais e que houve maior exportação de ganhos econômicos para fora da região que o que aqui se investia, entre outras, podemse pesquisar em Galeano (1983, p. 224 a 243) e Puyana (2008, p. 84). 
créditos para a região em um montante de US\$20 bilhões em um prazo de dez anos, empréstimos que eles mesmos entendiam como ajuda ou cooperação internacional. Não obstante o fato de todas as fontes parecerem concordar que tal montante não foi atingido, grande parte delas salienta que auxiliaram efetivamente as economias latino-americanas. Entretanto, tende-se a destacar que as que obtiveram mais benefícios teriam sido as economias que ofertavam os créditos, porque os recursos se transformavam em onerosas dívidas, pois estavam condicionados a serem utilizados em empreendimentos que não concorressem com a produção dos países provedores de capitais e porque uma parte importante deveria ser gasta em bens ou serviços do mesmo país que fornecia o dinheiro, sem importar se isso era ou não conveniente para os endividados.

Como uma tentativa de não depender dos duvidosos mecanismos de cooperação descritos, durante a década de 1960 nossos países fortalecem uma estratégia de industrialização que já tinha sido aplicada satisfatoriamente durante os anos da segunda guerra mundial e que na Europa também estava sendo considerada: a ampliação dos mercados nacionais por meio da integração regional. Em 1960, ergue-se o Mercado Comum Centro-americano e a Associação Latino-americana de Livre Comércio (denominadaAssociação Latino-americana de Integração, desde 1980), em 1965, cria-se a Associação de Livre Comércio do Caribe (Comunidade do Caribe desde 1975) e, em 1969, oficializa-se o Pacto Andino. Mesmo nas ocasiões em que essas iniciativas propiciaram um significativo crescimento no intercâmbio comercial, elas não puderam satisfizer as altas expectativas que acompanharam sua fundação e, finalmente, a instabilidade política dos governos nacionais junto à resistência de alguns atores econômicos, tanto de dentro como de fora da região, lhes superaram.

Na década de 1970, quando os capitais internos e as filiais das empresas multinacionais já tinham sido considerados como insuficientes, e quando começavam a amadurecer os juízos sobre a ineficácia dos empréstimos oficiais e da ineficiência dos esforços em prol da integração regional, outro fenômeno econômico que fugia ao controle dos países da região veio de encontro a eles. O 
petróleo, insumo vital para o modelo adotado, subiu bruscamente de preço e obrigou nossos países a se sobre-endividarem para poder custeá-lo, sendo agora os bancos privados internacionais os responsáveis por facilitar os recursos necessários para viabilizar os processos de industrialização, os mesmos recursos que obtinham dos excedentes que depositavam os países produtores de petróleo como resultado desta operação.

No final dos anos 1970 e começo dos anos 1980, pouco tempo depois de uma parte importante destes créditos já não ser mais usada para fins produtivos (apenas para manter a burocracia pública funcionando ou para pagar antigos empréstimos) o fluxo externo de divisas se interrompeu e de imediato se reverteu. Esse término dos recursos estrangeiros para financiar o crescimento das economias latino-americanas e a obrigação de cumprir com os compromissos financeiros adquiridos, traduz-se em uma imediata desindustrialização de nossas sociedades e em um aumento sem par do desemprego, da escassez e da pobreza. Panorama que levou alguns analistas a entenderem que os anos 1980 foram uma década perdida para a economia latino-americana. Outros, como o economista mexicano Victor Urquidi, consideravam a crise que explodiu naquele ínterim vinha incubando-se há décadas, talvez séculos (URQUIDI, p. 512).

A máxima que se escutava nos mais diversos tons e sob as mais diferentes bandeiras era que seria preciso fazer crescer a economia. Tinha-se que conseguir que nossas sociedades alcançassem os níveis de bem-estar das mais pujantes economias globais. Não obstante, ainda que tal crescimento tenha ocorrido (pois não em vão o terceiro quarto do século XX é identificado por alguns como a idade de ouro das economias latino-americanas) a pobreza e a distribuição da riqueza aumentaram a níveis vertiginosos. Cresceu a desigualdade entre os setores sociais, entre as áreas rurais e urbanas, entre os setores de cada país, entre os países e, como se não bastasse, entre a América Latina e as nações mais industrializadas. Em uma espécie de jogo de estratégia global em que sempre participamos em lastimáveis condições, em que nunca encontramos uma forma satisfatória de gerar os recursos 
necessários para viabilizar uma industrialização capaz de melhorar os níveis de vida do conjunto da população, pouco a pouco a dimensão econômica, como bem o entende o ensaísta uruguaio Eduardo Galeano, foi-se transformando em uma viajem com mais náufragos que navegantes. ${ }^{10}$

\section{TENSÕES POLÍTICAS NOS ANOS REVOLUCIONÁRIOS}

Em muitos momentos do século XX as dificuldades econômicas foram de tal magnitude que as fórmulas políticas tradicionais - populismos incluídos - viram-se ultrapassadas. Especialmente entre 1950 e 1980 não foi difícil constatar que, ao mesmo tempo em que as espirais de violência cresciam, as lideranças civis abandonavam a direção de nossas sociedades em favor de homens armados. Praticamente nenhum país da região pôde livrar-se dos golpes de Estado ou das guerras intestinas. Estes fenômenos políticos, sobre suas particularidades e características compartidas, serão aprofundados nesta seção. ${ }^{11}$

Ainda que a imagem predominante que se tem das ditaduras na América Latina seja de que foram de direita e que estas entendiam o mercado como o grande responsável por articular a convivência em sociedade ou que o senso comum considere as guerrilhas como movimentos de esquerda, que confiavam na capacidade do Estado para dirigir os destinos da coletividade, a história mostra que estas associações não foram a regra. Houve vários golpes de Estado que se apoiaram em ideários de esquerda, como o que se impôs no Peru em 1968, e que deram sequência os golpes de Equador, Bolívia, Honduras e Panamá. Assim como houve também vários grupos de direita que optaram pelas armas como principal argumento, como as assim chamadas guardas brancas que organizaram os fazendeiros brasileiros na metade do

10 A expressão de Eduardo Galeano foi retirada de Galeano (1983, p. 267).

11 Sobre o fenômeno político conhecido como populismo pode-se consultar, entre outras fontes, Braun (2008, p. 393). A interpretação alusiva a que a violência institucional, seja dos representantes estaduais ou os aspirantes a ele, é um sinal dos fracassos dos populismos, constrói-se com base em Devés (2003, p. 135), De la Peña (1997, p. 280) e Rama (1987a, p. 41) . 
século (com o objeto de neutralizar a iminente reforma agrária), ou como os esquadrões da morte salvadorenhos que, apenas em 1980, mataram aproximadamente três mil pessoas. ${ }^{12}$

Outro aspecto que compartilharam tanto guerrilhas como ditaduras foi que suas lideranças pertenciam aos emergentes setores médios da sociedade, que surgiram com o início da industrialização e da urbanização. Que os militares pertençam ao amplo espetro dos setores médios não requer maior discussão, afinal todos recebiam salário. Mais importante é salientar que as lideranças guerrilheiras também pertenciam a estes setores. As lideranças máximas dos rebeldes cubanos eram profissionais liberais. No México e no Peru foram os professores que nos anos 1960 lideraram algumas guerrilhas, assim como foram clérigos, militares e estudantes universitários os que tomaram parte na direção de uma parcela importante das guerrilhas centro-americanas, brasileiras e venezuelanas nos anos sessenta. As análises do sociólogo brasileiro Marcelo Ridenti sobre a origem dos membros das organizações armadas da esquerda brasileira, permitem avaliar que a maioria era composta de estudantes universitários ou profissionais jovens, muitos deles naturais do interior, mas que residiam nas capitais estaduais, ou seja, imigrantes. ${ }^{13}$

Ainda que as condicionantes econômicas sejam fulcrais para entender a aparição das ditaduras e das guerrilhas, tanto umas como outras justificavam seu agir como a única via possível para desenvolver o país. Objetivo que seria conquistado após livrar a sociedade de todos os males que a atrapalhavam, sobretudo daquele que se considerava como o maior de todos: a guerrilha para os golpistas, a ditadura para os guerrilheiros. Por isso, enquanto uns violentavam para manter a ordem e propiciar o crescimento

12 A ideia de que as ditaduras e guerrilhas na América Latina foram de direita e esquerda, e que a violência institucionalizada não foi usada apenas em governos comandados por militares, é tomada de Angell (2008, p. 354, 355 e 362). Sobre as ditaduras de esquerda nomeadas, podem-se consultar Angell (1997, p. 73, 110 e 111), Prieto (2009, p. 238) e Rouquié e Suffern (1997, p. 306-311). Sobre as organizações armadas de direita, paraestatais, podem ser encontradas referências em De la Peña (1997, p. 257) e Marini (1969, p. 59).

13 A associação entre vanguarda e setores médios é bem descrita em Ridenti (2010a, p. 385, 386-389; 2010b, p. 116, 117, 147, 209, 235 e 236). 
econômico, outros o faziam para impor outra ordem e impulsionar o crescimento econômico. Sempre existiram, portanto, boas, justas e coerentes razões para justificar a violência. Dentre estas razões, a mais transversal foi aquela que considerava que os políticos e a política convencional deviam ser substituídos, por terem dado provas suficientes de sua incapacidade para resolver os conflitos, canalizar o progresso e/ou manter a paz. ${ }^{14}$

Dentre todos os golpes de Estado, o que afetou a Guatemala, em 1954, tem um valor especial porque a ativa participação da inteligência estadunidense o fez entender, como sugere o historiador argentino Tulio Halperin Donghi, como a primeira manifestação concreta da guerra fria na região, consequência da disputa pela hegemonia mundial que mantiveram os Estados Unidos e a União Soviética, após a segunda guerra mundial. ${ }^{15}$ Este golpe assinala, por sua vez, a reativação das intervenções militares estadunidenses na América Latina após duas décadas de abstinência, intervenções que se amparavam na assinatura do Tratado Interamericano de Assistência Recíproca realizado no Rio de Janeiro em 1947 e que se apoiavam na academia militar que os estadunidenses instalaram no Panamá em 1948 para incidir sobre a oficialidade latino-americana, a Escola das Américas. A doutrina da segurança nacional, horizonte ideológico no qual se instruiria a nossos militares, substituía a concepção tradicional sobre sua missão, que consistia na defesa do país diante das ameaças externas, por outra, em que a defesa devia fazer-se frente às ameaças internas, chamem-se elas comunismo ou mesmo reformismo.

$14 \mathrm{O}$ argumento de que a violência institucionalizada é uma consequência das tensões econômicas e que se justifica pela necessidade de acabar com a guerrilha, segundo uns, ou com a ditadura, segundo outros, constrói-se a partir da visão de Angell (2008, p. 358-360), Rouquié e Suffern (1997, p. 281), Ridenti (2010b, p. 291) e Vasconi (1996, p. 7 e 8). Sobre as noções contrárias aos políticos e à política convencional consultar, entre outras fontes, Angell (2008, 358 e 359), Lewis (2008, p. 279) e Rouquié e Suffern (1997, p. 286 e 289). Algumas alusões a respeito da violência como ferramenta para defender a democracia ou a paz, tanto na América Latina como em outras latitudes, podem ser encontradas em Hartlyn e Valenzuela (1997, p. 17) e Zizek (2008, p. 63-66). 15 Sobre a guerra fria na América Latina e a influência dos Estados Unidos no golpe na Guatemala, veja-se Halperin (1969, p. 436 e 437), Angell (1997, p. 97 e 98), Braun (2008, p. 373), De la Peña (1997, p. 229), Prieto (2009, p. 200 a 205) e Sader (2000, p. 102). 
Após a invasão sofrida pela Guatemala, outros países - entre eles Cuba, República Dominicana, Nicarágua, Granada e Panamá - sofreram ataques militares diretos ou indiretos por parte dos Estados Unidos. Como bem soube ler uns dos afetados por estas agressões, o outrora presidente da República Dominicana Juan Bosch, elas não perseguiam desdobrar-se em uma estratégia imperialista como aquela que até então se conhecia, baseada na ocupação de territórios com vistas a sua exploração econômica. Pretendiam, mais pontualmente, manter aos Estados Unidos em uma guerra permanente, pois dessa maneira crescia sua indústria militar, seu principal negócio, e se podia obter, com o triunfo, o controle indireto dos territórios através de autoridades locais dispostas a favorecer seus interesses convencionais. ${ }^{16}$ Essa lógica também atuou no pano de fundo das operações dos Estados Unidos na guerra entre Honduras e El Salvador em 1969, pois, não contentes em assessorar a oficialidade dos dois exércitos, venderam a ambos seus armamentos usados.

Esta estratégia estadunidense, ainda vigente, era-lhes duplamente favorável, porque lhes permitia manter-se no patamar de grande potencia militar e econômica, e lhes ajudava a conservar limpa sua imagem internacional ao apresentá-los como interessados em salvar, libertar ou ajudar aos países afetados. Deve-se reparar, ademais, que a região não foi a única que se viu "beneficiada" por estas expurgações, uma vez que, depois de acabada a segunda guerra mundial, a indústria militar dos países beligerantes se dedicou a prover de armamento os participantes dos mais de cento e cinquenta conflitos armados que se sucederam nos países pobres da África, da Ásia e da América Latina. ${ }^{17}$

16 O novo imperialismo, chamado por Juan Bosch "Pentagonismo", pode ser estudado em Bosch (1968, p. 20, 21, 26, 27, 70, 85-88) e também em Sader (2000, p. 114).

17 Estas vantagens do pentagonismo são sinalizadas muito cedo por Bosch (1968, p. 27 e 28). Um daqueles que melhor desmascara os vínculos entre o desenvolvimento e a indústria militar é Arturo Escobar, sendo eles, assinala, os responsáveis pelas dezenas de guerras travadas no terceiro mundo com armamentos provenientes do primeiro, ver Escobar (2007, p. 69). Esta reflexão é sustentada também em Sader (2000, p. 111). 
Se o ano 1954 foi chave para as ditaduras, 1959 o será para as guerrilhas. Pouco depois dos incidentes na Guatemala, impôs-se em Cuba pela primeira vez um movimento armado com essas características. Dentre as principais repercussões que a vitória rebelde teve na América Latina, destacaram-se duas: por um lado, ela mudou os parâmetros do possível ao remover a certeza de que toda mudança devia contar com o beneplácito dos Estados Unidos; por outro lado, deu um grande impulso às guerrilhas em toda a região. Sem pretender fazer uma retomada exaustiva, lembra-se apenas que, só no primeiro ano da revolução cubana, criaram-se focos guerrilheiros na Argentina, Panamá, Haiti, Equador e República Dominicana. No ano seguinte, 1960, levantou-se a guerrilha paraguaia; em 1962, iniciaram-se ações na Venezuela e, entre 1963 e 1965, levantaram-se focos novamente na República Dominicana, enquanto no Peru ganharam impulso várias iniciativas. Em 1966, no entanto, ganhou corpo a guerrilha boliviana, a qual não só contou com apoio militar e econômico cubano como também foi dirigida por seu segundo homem, Ernesto Guevara. Como parte desta mesma onda guerrilheira se consigna que, em meados dos anos sessenta, começaram a operar grupos armados em Montevidéu, Buenos Aires, São Paulo, Rio de Janeiro, Caracas e outras cidades da região.

Frente a esta arremetida das guerrilhas, as ditaduras não tardaram. Foram nove as que se instalaram na região só entre os anos 1962 e 1966. Todos os governos que se consideraram ineficientes frente ao comunismo, ou pouco efusivos em suas mostras de apoio aos Estados Unidos, estiveram na mira de golpistas. A tal grau chegaram os vínculos entre as ditaduras e os Estados Unidos que, em 1964, seu secretário adjunto de assuntos latino-americanos, Thomas Mann, transparentou esta ordem de coisas ao confidenciar que, para estabelecer relações de cooperação com os governos da região, seu país não contemplaria o fato de que tivessem sido eleitos mediante comícios. ${ }^{18}$

18 O número de ditaduras surgidas nos anos posteriores à revolução cubana é obtido de Angell (1997, p. 103) e Hartlyn e Valenzuela (1997, p. 49). As razões que teriam motivado esses golpes se obtêm de Angell (1997, p. 103) e Rouquié 
De todas as ditaduras que se abateram sobre a América Latina nesses anos, a que se instaurou no Chile, em 1973, reveste-se de especial interesse tanto pelas implicâncias mesmas do golpe do Estado (impôs-se sobre um governo com um projeto socialista legitimado eleitoralmente) quanto pela inovadora estratégia econômica que assumiria (o neoliberalismo que depois seria a norma em quase toda a região). Como consequência dos múltiplos reveses que sofreu a estratégia guerrilheira impulsionada por Havana, a via eleitoral que promovia Santiago do Chile tinha começado a ser vista cada vez com maior ilusão por todos os que se dedicavam a achar caminhos para alcançar o socialismo. Tanta relevância adquiriu o processo chileno que o país, não obstante ser um dos menores da região e a não ter nenhuma guerrilha ativa, foi um dos que recebeu mais "cooperação" militar durante estes anos por parte dos Estados Unidos. Entre 1950 e 1970, obteve aproximadamente US\$120 milhões dessa maneira, ao que se deve agregar que mais de quatro mil militares passaram por alguma academia militar estadunidense. Uma vez instaurada a ditadura e silenciada a dissidência, os assessores econômicos dos militares, muitos deles formados nos Estados Unidos, impuseram o neoliberalismo em sua expressão mais ortodoxa. Depois da queda da via chilena ao socialismo, as guerrilhas voltaram a erguer-se em alguns pontos da região (com especial força na América Central) e as ditaduras continuaram vigorando durante uma boa quantidade de anos, não obstante em uma situação diferente de antes, pois a crise de hegemonia tinha sido resolvida.

A vida para os latino-americanos do século XX esteve lotada de constrições, dificuldades e crises. Os novos fenômenos econômicos e sociais, a industrialização e a urbanização, assim como seus problemas associados, abalaram todas as certezas culturais que até então existiam, aplanando assim o caminho para que o nacionalismo, em suas múltiplas variantes, arraigasse-se na consciência das pessoas. Enquanto a esfera econômica via fracassar a sucessão incessante das medidas que prometiam superar o

e Suffern (1997, p. 291). As alusões a Thomas Mann se adquirem de Halperin (1969, p. 462) e Marini (1969, p. 59). 
desemprego e a fome, na esfera política todas as estratégias para conseguir uma convivência harmônica foram sucedidas por ditaduras e guerrilhas que deixavam atrás de si rios de sangue derramado, uma série de expectativas frustradas e muitos dos problemas que se propunham solucionar intactos. Essa breve retomada das principais tensões culturais, econômicas e políticas que afetaram a região e que ainda lhe afetam, não só ajuda a conformar um mapa com os principais problemas que preocupavam aos latino-americanos e seus intelectuais, como também permitem compreender como a vida pôde transformar-se em uma luta para sobreviver no meio de um grande campo de batalha.

\section{REFERÊNCIAS}

$\mathrm{BOSCH}$, J. El pentagonismo sustituto del imperialismo. Madri: Guadiana de Publicaciones, 1968 [1967].

De Cristóbal Colón a Fidel Castro. El Caribe frontera imperial. Cidade do México: Editorial Miguel Ángel Porrúa, 2009 [1970].

BRAUN, H. Populismos latinoamericanos. In: PALACIOS, M; WEINBERG, G. Historia general de América Latina, tomo VIII. América Latina desde 1930. Paris: UNESCO - Editorial Trotta, 2008, p. 371-394.

Bulmer-Thomas, V. Las economías latinoamericanas 1929-1939. In: Bethell, L. (ed.) Historia de América Latina. Economía y sociedad desde 1930. Barcelona: Editorial Crítica, 1997 [1994], p. 3-46.

La historia económica de América Latina desde la independencia. Cidade do México: Fondo de Cultura Económica, 1998 [1994].

DE LA PEÑA, G. Las movilizaciones rurales en América Latina c. 1920. In: Bethell, L. (ed.) Historia de América Latina. Política y sociedad desde 1930. Barcelona: Editorial Crítica, 1997 [1994], p. 193-280.

DEVÉS, E. El pensamiento latinoamericano en el siglo XX. Entre la modernización y la identidad. Tomo 1, del Ariel de Rodó a la CEPAL (1900-1950). Buenos Aires: Editorial Biblos e Centro de Investigaciones Diego Barros Arana, 2000. 
. El pensamiento latinoamericano del siglo $\mathbf{X X}$. Desde la CEPAL al neoliberalismo (1950-1990). Buenos Aires: Editorial Biblos e Centro de Investigaciones Diego Barros Arana, 2003.

DONOSO ROMO, A. Identidad y educación en América Latina. Ensayos. Caracas: Editorial Laboratorio Educativo, 2012.

ESCOBAR, A. La invención del Tercer Mundo. Construcción y deconstrucción del desarrollo. Caracas: Fundación Editorial el Perro y la Rana, 2007.

Fals Borda, O. As revoluções inacabadas na América Latina (1 809-1968). São Paulo: Global Editora, 1979 [1968].

FERNÁNDEZ RETAMAR, R. Pensamiento de Nuestra América. Buenos Aires: CLACSO, 2006.

FFrench-Davis, R.; Muñoz, O.; Palma, J. G. Las economías latinoamericanas, 1950-1990. In: Bethell, L. (ed.) Historia de América Latina. Economía y sociedad desde 1930. Barcelona: Editorial Crítica, 1997 [1994], p. 83-161.

FUNES, P. Salvar la nación: intelectuales, cultura y política en los años veinte latinoamericanos. Buenos Aires: Prometeo Libros, 2006.

GALEANO, E. As veias abertas da América Latina. São Paulo: Editora Paz e Terra, 1983 [1971].

GONZÁLEZ CASANOVA, P. Imperialismo y liberación: una introducción a la historia contemporánea de América Latina. Cidade do México: Siglo XXI Editores, 1985 [1979].

HALPERIN, T. Historia contemporánea de América Latina. Madri: Alianza Editorial, 1969.

HARTLYN, J.; Valenzuela, A. La democracia en América Latina. In: BETHELL, L. (ed.) Historia de América Latina. Política y sociedad desde 1930. Barcelona: Editorial Crítica, 1997 [1994], p. 11-66.

HOBSBAWM, E. Era dos extremos. O breve século XX. 19141991. São Paulo: Companhia das Letras, 2003 [1994].

LEWIS, C. El Estado y el desarrollo económico. In: Palacios, M.; WEINBERG, G. Historia general de América Latina, tomo VIII. América Latina desde 1930. Paris: UNESCO - Editorial Trotta, 2008, p. 253-291. 
LONG, N.; ROBERTS, B. Las estructuras agrarias de América Latina, 1930-1990. In: Bethell, L. (ed.) Historia de América Latina. Economía y sociedad desde 1930. Barcelona: Editorial Crítica, 1997 [1994], p. 278-344.

MARICHAL, C. Los ciclos de la deuda externa en América Latina en el siglo XX: una historia recurrente. In: Palacios, M.; WEINBERG, G. Historia general de América Latina, tomo VIII. América Latina desde 1930. Paris: UNESCO - Editorial Trotta, 2008, p. 189-212.

MARINI, R. M. Subdesarrollo y revolución. Cidade do México: Siglo XXI Editores, 1969.

MARTÍ, J. Nuestra América. In: Fernández Retamar, R. (ed.) José Martí: Cuba, Nuestra América, los Estados Unidos. Cidade do México: Siglo XXI Editores, 1973 [1891], p. 111-120.

PALACIOS, M. Las sociedades agrarias en América Latina desde 1930 al presente. In: Palacios, M.; WEINBERG, G. Historia general de América Latina, tomo VIII. América Latina desde 1930. Paris: UNESCO - Editorial Trotta, 2008, p. 53-77.

PRIETO, A. Procesos revolucionarios en América Latina. Querétaro: Ocean, 2009.

PUYANA, A. La industrialización de América Latina y el Caribe. In: Palacios, M.; WEINBERG, G. Historia general de América Latina, tomo VIII. América Latina desde 1930. Paris: UNESCO Editorial Trotta, 2008, p. 81-104.

.; ROMERO, J.; TORRES, E. La inserción de América Latina y el Caribe en la Economía Mundial. In: PALACIOS, M.; WEINBERG, G. Historia general de América Latina, tomo VIII. América Latina desde 1930. Paris: UNESCO - Editorial Trotta, 2008, p. 151-188.

RAMA, G. (coord.) Desarrollo y educación en América Latina y el Caribe, tomo 1. Buenos Aires: CEPAL/UNESCO/PNUD/ Kapelusz, 1987a.

. (coord.) Desarrollo y educación en América Latina y el Caribe, tomo 2. Buenos Aires: CEPAL/UNESCO/PNUD/Kapelusz, $1987 \mathrm{~b}$.

RIDENTI, M. Artistas e intelectuales brasileños en la décadas de 1960 y 1970: cultura y revolución. In: ALTAMIRANO, C (dir.) 
Historia de los intelectuales en América Latina. Madri: Katz, 2010a, p. 372-394.

O fantasma da revolução brasileira. São Paulo: Editora UNESP, 2010b [1993].

RODÓ, J. E. Ariel, a la Juventud de América. In: RAMA, Á. (ed.) Ariel, motivos de Proteo. Biblioteca Ayacucho, 1976 [1900], p.156.

ROUQUIÉ, A.; Suffern, S. Los militares en la política latinoamericana desde 1930. In: BETHELL, L. (ed.) Historia de América Latina. Política y sociedad desde 1930. Barcelona: Editorial Crítica, 1997 [1994], p. 281-341.

ROXBOROUGH, R. La clase trabajadora urbana y el movimiento obrero en América Latina desde 1930. In: Bethell, L. (ed.) Historia de América Latina. Política y sociedad desde 1930. Barcelona: Editorial Crítica, 1997 [1994], p. 132-192.

SAID, E. Cultura e imperialismo. São Paulo: Companhia das Letras, 1999.

SADER, E. Século XX: uma biografia não autorizada. São Paulo: Editora Fundação Perseu Abramo, 2000.

THORP, R. Las economías latinoamericanas, 1939-1950. In: BETHELL, L (ed.) Historia de América Latina. Economía y sociedad desde 1930. Barcelona: Editorial Crítica, 1997 [1994], p. 47-82.

Progreso, pobreza y exclusión: una historia económica de América Latina en el siglo XX. Nova Iorque: BID, 1998.

URQUIDI, V. Otro siglo perdido. Las políticas de desarrollo en América Latina (1930-2005). Cidade do México: Fondo de Cultura Económica, 2005.

VASCONI, T. Las ciencias sociales en América del Sur y Chile. Santiago do Chile: Centro de Investigaciones Sociales Universidad ARCIS, 1996 [1991].

ZIZEK, S. En defensa de la intolerancia. Madri: Ediciones Sequitur, 2008. 